\title{
Pengajian Kitab Akhlak Lil Banin Juz Pertama bagi Remaja Masjid Al-Mukhlisin Desa Air Bagi Kecamatan Concong
}

\author{
${ }^{*}$ Abd. Syahid ${ }^{1)}$ Syamsiah Nur $^{2)}$ Masriani $^{3)}$, Hasnawati ${ }^{4)}$ \\ 1,2,4) Program Studi PAI STAI Auliaurrasyidin, Indragiri Hilir, Riau Indonesia \\ ${ }^{3)}$ Program Studi PGMI STAI Auliaurrasyidin, Indragiri Hilir, Riau Indonesia

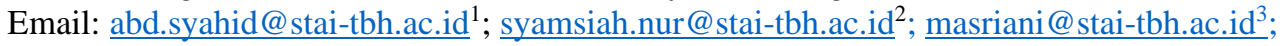 \\ hasnawati@stai-tbh.ac.id ${ }^{4}$
}

\section{Cara Mensitasi Artikel ini:}

Syahid, A., Nur, S., Masriani, M., \& Hasnawati, H. (2021). Pengajian kitab Akhlak Lil Banin juz pertama bagi remaja masjid Al-Mukhlisin Desa Air Bagi Kecamatan Concong. Abdimasy: Jurnal Pengabdian dan Pemberdayaan Masyarakat, 2(2), 105-115. https://doi.org/10.46963/ams.v2i2.462

\section{$\underline{\text { DOI }}$}

https://doi.org/10.46963/ams.v2i2.462

\section{Sejarah Artikel}

Diterima : 25/12/2021

Direvisi : :28/12/2021

Diterbitkan : 31/12/2021

\section{*) Corresponding Author}

Abd.syahid@stai-tbh.ac.id

\section{Editorial Address}

Kampus Panam (Parit Enam)

STAI Auliaurrasyidin, Jl. Gerilya No. 12 Tembilahan Barat, Riau, Indonesia, 29213

abdimasy@stai-tbh.ac.id

Kata Kunci:

Kitab; Akhlak; Lil Banin

Keywords:

Book; Moral; Lil banin
Abstract: The author of the Book of Al-Akhlak Lil Banin is AlUstadz 'Umar bin Achmad Baradja, he is a scholar who has very noble character. Since childhood he was raised and educated by his maternal grandfather, Shaykh Hasan bin Muhammad Baradja, a scholar of nahwu and figh. Nasab Baradja comes from Seiwun, Hadramaut, Yemen. The spirit of struggle carried out by Al-Ustadz 'Umar bin Achmad Baradja to spread religion and form good moral character in early childhood in Indonesia in general and in Ampel in particular, who saw the moral damage that had undermined the morals of teenagers at that time. So that Al-Ustadz 'Umar Baradja composed as well as compiled the book Al-Akhlak Lil Banin to guide them to always do positive things, such as keeping their bodies clean, clothes, to morals to Allah SWT, parents, teachers, friends and so on., and the character most described by him is the character of social care. The problems that will be discussed are, (1) Who is Al-Ustadz 'Umar Baradja and his activities (2) What is the thought of Al-Ustadz. 'Umar Baradja in the book Al-Akhlak Lil Banin. The thoughts of Al-Ustadz 'Umar Baradja in the book Al-Akhlak Lil Banin are more focused on special morals for boys, because they are prepared for the future to become leaders. If he grows up in noble character and grows up with the right education, he will also become a role model and be obeyed by his children in particular and the wider community in general.

Abstrak: Penulis Kitab Al-Akhlak Lil Banin adalah Al-Ustadz 'Umar bin Achmad Baradja beliau seorang ulama yang memiliki akhlak yang sangat mulia. Sejak kecil dia diasuh dan dididik kakeknya dari pihak ibu, Syaikh Hasan bin Muhammad Baradja, seorang ulama ahli nahwu dan fikih. Nasab Baradja berasal dari Seiwun, Hadramaut, Yaman. Semangat perjuangan yang dilakukan oleh Al-Ustadz 'Umar bin Achmad Baradja untuk menyebarkan agama serta membentuk karakter akhlak yang baik pada anak usia dini di Indonesia umumnya dan di Ampel khususnya, yang melihat kerusakan moral yang telah menggerogoti akhlak anak remaja saat itu. Sehingga Al-Ustadz 'Umar Baradja mengarang sekaligus menyusun kitab Al-Akhlak Lil Banin untuk membimbing mereka agar selalu melakukan halhal yang positif, seperti kebersihan menjaga badan, pakaian, 
sampai akhlak kepada Allah SWT, orang tua, guru, teman dan lain sebagainya, dan karakter yang paling banyak dijelaskan oleh beliau adalah karakter peduli sosial. Permasalahan yang akan dibahas yaitu, (1) Siapa Al-Ustadz 'Umar Baradja dan aktivitasnya (2) Bagaimana pemikiran Al-Ustadz 'Umar Baradja dalam kitab Al-Akhlak Lil Banin. Pemikiran Al-Ustadz 'Umar Baradja dalam kitab Al-Akhlak Lil Banin lebih fokus tentang akhlak khusus bagi anak laki-laki, karena mereka dipersiapkan untuk zaman yang akan datang menjadi sosok pemimpin. Apabila ia besar dalam akhlak yang mulia dan tumbuh dengan pendidikan yang benar, maka ia pun akan menjadi sosok panutan dan dipatuhi oleh anak-anaknya pada khususnya dan masyarakat luas pada uтитпуa.

This work is licensed under a Creative Commons Attribution-ShareAlike 4.0 International License (CC-BY-SA)

\section{PENDAHULUAN}

Kitab Akhlak Lil Banin adalah sebuah Kitab yang disusun oleh Ustadz Umar Achmad Baraja yang membahas seputar Akhlaq (Sopan santun /Adab) yang di dalamnya terdiri dari beberapa bab. Bahasa arab yang digunakan di dalam kitab ini tergolong mudah karena bisa diterjemahkan baik secara Kinayah maupun Lafdziyah, selain itu isi dari kitab ini mudah sekali dicerna, karena bahasa yang digunakan sesuai dengan peruntukkannya. Sebagaimana nama dari kitab ini kalau diterjemahkan Akhlak untuk anak laki-laki (Lil Banin) meskipun dalam kenyataan bisa digunakan juga untuk anak perempuan (Lil Banat).

\section{Riwayat Hidup Pengarang Kitab}

Syaikh Umar bin Achmad Baradja adalah seorang ulama yang memiliki akhlak yang sangat mulia. Beliau lahir lahir di kampung Ampel Maghfur, pada 10 Jumadil Akhir 1331 H/17 Mei 1913 M. Sejak kecil dia diasuh dan dididik kakeknya dari pihak ibu, Syaikh Hasan bin Muhammad Baradja, seorang ulama ahli nahwu dan fiqih. Nasab Baradja berasal dari (dan berpusat di) Seiwun,
Hadramaut, Yaman. Sebagai nama nenek moyangnya yang ke-18, Syaikh Sa'ad, laqab (julukannya) Abi Raja' (yang selalu berharap). Mata rantai keturunan tersebut bertemu pada kakek Nabi Muhammad SAW yang kelima , bernama Kilab bin Murrah.

Penampilan Syeikh Umar sangat bersahaja, tetapi dihiasi sifat-sifat ketulusan niat yang disertai keikhlasan dalam segala amal perbuatan duniawi dan ukhrawi. Dia juga menjabarkan akhlak Ahlul Bait, keluarga Nabi dan para sahabat, yang mencontoh baginda Nabi Muhammad SAW. Dia tidak suka membangga-banggakan diri, baik tentang ilmu, amal, maupun ibadah. Ini karena sifat tawadu' dan rendah hatinya sangat tinggi. Dalam beribadah, dia selalu Istiqamah baik Shalat fardu maupun sholat sunnah qabliyah dan ba'diyah. Sholat dhuha dan tahajud hampir tidak pernah dia tinggalkan walaupun dalam bepergian. Kehidupannya dia usahakan untuk benar-benar sesuai dengan yang digariskan agama. Cintanya kepada keluarga Nabi SAW dan dzurriyyah atau keturunannya, sangat kenal tak tergoyahkan. Juga kepada para sahabat 
anak didik Rasulullah SAW. Itulah pertanda keimanan yang teguh dan sempurna.

Pada saat sebelum mendekati ajalnya, Syaikh umar sempat berwasiat kepada putra-putra dan anak didiknya agar selalu berpegang teguh pada ajaran assalaf asshalih. Yaitu ajaran Ahlussunnah wal Jama'ah, yang dianut mayoritas kaum muslim di Indonesia dan Thariqah 'Alawiyyah, dan bermata rantai sampai kepada ahlul bait Nabi, para sahabat, yang semuanya bersumber dari Rasulullah SAW. Syaikh Umar memanfaatkan ilmu, waktu, umur, dan membelanjakan hartanya di jalan Allah sampai akhir hayatnya. Ia memenuhi panggilan Rabbnya pada hari Sabtu malam Ahad tanggal 16 Rabiuts Tsani 1411 H/3November 1990 M pukul 23.10 WIB di Rumah Sakit Islam Surabaya, dalam usia 77 Tahun. Keesokan harinya Ahad ba'da Ashar, ia dimakamkan, setelah disalatkan di Masjid Agung Sunan Ampel, diimami putranya sendiri yang menjadi khalifah (penggantinya), Al-Ustadz Ahmad bin Umar Baradja. Jasad mulia itu dikuburkan di makam Islam Pegirian Surabaya. Prosesi pemakamannya dihadiri ribuan orang.

\section{METODE}

Sasaran pengabdian ini ditujukan Bagi Remaja Masjid Al-Mukhlisin Desa Air Bagi Kecamatan Concong. Dalam kegiatan pengabdian masyarakat ini untuk memastikan tujuan dari pelaksanaan ini dapat terlaksana dengan baik, maka ada beberapa tahapan yang dapat dilakukan, yaitu :

Pertama, sosialisasi. Kegiatan ini dilakukan melalui pemberian pembekalan
Pengajian Kitab Akhlak Lil Banin Juz Pertama Bagi Remaja Masjid AlMukhlisin Desa Air Bagi Kecamatan Concong. Tahapan ini bertujuan untuk mengedukasi kepada remaja jamaah masjid tentang pentingnya pendidikan akhlak yang baik dan mantap dalam kehidupan seorang muslim. Kemudian sosialisasi ini juga disertai dengan tujuan untuk meningkatkan keimanan dan berbuat amal Shaleh di setiap kesempatan sesuai dengan kemampuan, karena ini sangat penting, karena merupakan pokok yang wajib diketahui oleh seorang muslim.

Kedua, Pengajian ini dilaksanakan bersama-sama dengan santri, guru membacakan seterusnya santri mengikuti

Ketiga, Pengajian Kitab Akhlak Lil Banin Juz Pertama, dikhususkan kepada remaja Masjid Al-Mukhlisin Desa Air Bagi Kecamatan Concong dan jamaah lain yang berada di kecamatan concong.

\section{HASIL DAN PEMBAHASAN}

Pengajian Kitab Akhlak Lil Banin Juz Pertama Bagi Remaja Masjid AlMukhlisin Desa Air Bagi Kecan 56 Concong. Adapun materi kegiatan diambil dari kitab akhlak lil banin juz pertama. Adapun materi pembahasan dalam kitab ini lebih jelasnya yaitu;

1. Dengan Apa Seorang Anak Beradab? (1) Wajib atas seorang anak berakhlak dengan akhlak yang baik dari kecilnya, agar kehidupannya dicintai ketika dewasa: Tuhannya akan Ridho padanya, dan keluarganya akan senantiasa mencintainya, dan seluruh manusia. (2) Wajib juga atas seorang anak yang beradab, Menjauhi dari akhlak yang tercela, agar tidak 
Pengajian kitab akhlak lil banin juz pertama bagi remaja masjid Al-Mukhlisin .....

menjadi orang yang dibenci: Tuhannya tidak Ridho padanya, dan keluarganya tidak mencintainya dan juga seluruh manusia.

2. Anak Yang Santun dan Beradab. (1) Seorang anak yang beradab ia memuliakan kedua orang tuanya dan para pengajarnya, dan para saudaranya yang lebih besar, dan semua orang yang lebih besar darinya, dan menyayangi saudaranya yang lebih kecil, dan semua orang yang lebih kecil darinya. (2) Dan seorang anak yang beradab selalu jujur dalam setiap perkataannya, dan bertawadu (rendah hati) sesama manusia, dan bersabar atas gangguan dan tidak memutuskan hubungan dengan anak-anak (tetangga), tidak pula berkelahi bersama mereka, dan tidak meninggikan suara apabila sedang berbicara atau tertawa.

3. Anak Yang Buruk Akhlak. Seorang anak yang jelek: ia tidak beradab kepada kedua orang tuanya dan para ustadz-ustadznya, ia tidak menghormati orang yang lebih tua darinya, ia tidak menyayangi orang yang lebih muda darinya, ia selalu berbohong apabila berkata-kata, dan mengangkat suaranya apabila tertawa, dan ia suka memaki, dan berkata yang tercela, dan bertengkar serta memperolok-olok orang lain, dan ia menyombongkan diri, dan ia tidak malu kalau berbuat yang tercela, dan ia tidak suka mendengar nasihat.

4. Seorang Anak Wajib Beradab Sejak Dari Kecilnya. Ahmad seorang anak kecil, akan tetapi ia beradab, oleh karna itu ayahnya mencintainya, dan ia juga suka bertanya dari segala sesuatu yang ia tidak mengerti. Pada suatu hari ia berjalan ${ }^{2}$ bersama ayahnya ke kebun, maka ia melihat pohon bunga yang indah, akan tetapi pohon itu bengkok. Maka Ahmad bertanya: Betapa indahnya pohon ini! Akan tetapi mengapa ia bengkok wahai ayahku? Sang Ayah menjawab: Karena Tukang Kebun tidak memperhatikan serta tidak meluruskannya semenjak dari kecilnya, maka jadilah ia bengkok; Lebih baik, kita meluruskannya saja sekarang, ujar Ahmad, Maka tertawa sang Ayah, dan berkata: Tidak Mudah yang demikian itu wahai Anakku, karena ia sudah tumbuh besar, dan ranting²nya pun tebal. Beginilah seorang anak yang tidak beradab dari kecilnya, tidak mungkin ia beradab pada waktu ia telah besar.

5. Allah Yang Maha Suci lagi Maha Tinggi. (1) Wahai anak yang mulia :Allah yang Maha Suci lagi Maha Tinggi Dia yang menciptakanmu, dan membaguskan rupamu, dengan memberi kedua mata kepadamu dengannya kamu bisa melihat segala sesuatu, dan kedua telinga, dengannya kamu bisa mendengar suara, dan lisan yang dengannya kamu mampu berbicara, dan kedua tangan yang dengannya kamu mampu memakai untuk aktivitasmu, dan kedua kaki yang dengannya kamu bisa berjalan, dan akal yang dengannya kamu mengetahui yang baik dari yang buruk, dan Dia memberi nikmat atasmu berupa kesehatan yang sehat, serta meletakkan rasa sayang di hati kedua 
orang tuamu sehingga mereka mendidikmu dengan pendidikan yang baik. (2) Maka wajib atasmu untuk mengagungkan serta mencintai Tuhanmu, dan engkau mensyukuri atas segala nikmat-nikmat-Nya : dengan kamu mematuhi segala perintah-perintah-Nya, dan menjauhi segala larangan-Nya, dan juga kamu mengagungkan seluruh para Malaikatmalaikat-Nya, Rasul-rasul-Nya, NabiNabi-Nya dan seluruh orang-orang Shaleh dari semua hamba-hamba-Nya, dan kamu cintai mereka karena sesungguhnya Allah yang Maha Tinggi mencintai mereka. (3) Apabila kamu telah mencintai Tuhanmu, dan mematuhi segala perintah-perintahNya serta menjauhi semua laranganlarangan-Nya, Dia akan menambah nikmat-nikmat-Nya kepadamu, dan menjadikanmu orang yang dicintai diantara manusia, serta menjagamu dari segala gangguan, dan memberi mu segala apa-apa yang kamu mau: dari pada rezeki atau yang lainnya.

6. Anak Yang Jujur. Muhammad seorang anak yang jujur, ia takut kepada Allah, dan ia mematuhi segala perintah-Nya. Pada suatu hari berkata kakak perempuannya yaitu Suad: Wahai saudaraku, sesungguhnya Ayah kita telah keluar dari rumah, maka marilah kita buka lemari makanan untuk kita makan apa-apa yang ada di dalamnya dari pada makanan yang lezat, karena Ayah tidak akan melihat kita; Maka Muhammad menjawab, Benar sekali wahai saudaraku, sesungguhnya Ayah kita tidak melihat kita, akan tetapi apakah engkau mengetahuinya bahwa sesungguhnya Allah lah yang melihat kita; Maka hati-hatilah semisal perbuatan tercela ini, karena sesungguhnya kalau engkau mengambil sesuatu dengan tanpa Ridho Ayahmu, maka sesungguhnya Allah murka terhadapmu, dan Dia kelak akan memberi hukuman kepadamu. Maka takutlah adalah, dan malu atas keburukan niatnya, dan ia berkata, Benar kata-katamu wahai saudaraku, dan aku bersyukur sekali atas nasihat yang baik ini; ujar Suad.

7. Anak Yang Taat. Hasan adalah seorang anak yang taat, ia shalat setiap hari, shalat lima waktu, dan ia selalu lazim hadir di madrasah untuk membaca Al-Quran, dan mengulangulang pelajarannya di rumah, dengan begitu ia disukai ayah dan ibundanya, dan para guru-gurunya dan seluruh manusia. dan dari kebiasaannya apabila ingin tidur : dan hendaknya ia mengingat Allah, serta bersyukur atas penjagaan-Nya sepanjang hari 58 segala bencana dan gangguan, kemudian ia berdoa; dengan Nama Allah saya hidup dan dengan namaNya saya mati. Dan apabila ia telah bangun dari tidurnya, ia bersyukur kepada Allah atas nikmat tidur, dan berdoa; Segala puji bagi Allah yang menghidupkan kami setelah matinya kami dan kepada-Nya lah kami kembali. Dan dari kebiasaannya juga apabila makan : maka ia berkata Bismillah terlebih dahulu, dan apabila ia selesai dari makannya, ia bersyukur atas nikmat makan, karna sesungguhnya ia mengetahui bahwa Allah yang memberikan makanan 
Pengajian kitab akhlak lil banin juz pertama bagi remaja masjid Al-Mukhlisin .....

kepadanya, dan berdoa; Alhamdulillahi ladzi Ath'amany hazdath Tho'aman wa rozaqonihi min ghoiri haulin minni wa laa quwwah. Betapa bahagianya anak yang taat ini: Tuhannya akan ridho padanya dan kelak akan dimasukkannya ke dalam surga.

8. Nabimu Muhammad Shallallahu 'Alaihi wa Aalihi wa Sallam. (1) Wahai anak yang beradab: sebagaimana wajib atasmu untuk mengagungkan Tuhanmu yang Maha Suci lagi Maha Tinggi, wajib juga atasmu untuk mengagungkan Nabimu Muhammad Shallallahu 'Alaihi wa Aalihi wa Sallam, dan memenuhi hatimu dengan mencintainya sehingga rasa mencintainya lebih banyak/besar dari rasa cintamu terhadap kedua orang tuamu dan terhadap dirimu sendiri. Karena sesungguhnya beliau yang mengajarkan kita akan agama Islam, dan dengan sebabnya kita mengetahui Tuhan kita, dan kita mampu membedakan antara yang halal dan yang haram. Karena sesungguhnya Allah Ta'ala mencintainya (Nabi Muhammad Shallallahu 'Alaihi wa Aalihi wa Sallam), maka Dia (Allah) Menjadikannya (Nabi Muhammad) sepaling unggul/utamanya manusia, serta menjadikannya contoh/panutan bagi kita di dalam akhlak-akhlak dan adab-adabnya. (2) Apabila engkau telah mencintai Nabimu, maka ikutilah di dalam perjalanannya, dan beramal dengan nasihat-nasihatnya agar engkau mendapat cinta dan ridho-Nya Allah.
9. Akhlak Di Rumah. (1) Wajib atas seorang anak untuk memperhatikan adab di dalam rumahnya, dengan menghormati kedua orang tuanya, dan saudara-saudara laki-lakinya ataupun kepada saudari perempuannya, dan semua orang di dalam rumahnya, dan tidak melakukan sesuatu yang membuat salah satu dari mereka menjadi marah, dan tidak membantah saudaranya yang lebih besar serta memusuhi saudaranya yang lebih kecil darinya, dan tidak menyakiti para pembantu, dan apabila bermain maka bermainlah dengan disiplin, dengan tanpa berteriak-teriak dan tidak bergerak (berlaga) yang tidak sesuai, terutama apabila ada seseorang di rumah yang sedang tidur atau sedang sakit. (2) Dan memelihara terhadap alat-alat rumah, maka tidaklah memainkan alat-alat dapur, dan tidak mendobrak pintu, merusak pepohonan, dan apabila ada padanya kucing atau ayam, maka hendaknya ia memberi kepadanya makan-makanan dan minum-minuman dan jangan menyakitinya.

10. Abdullah Di Rumahnya. Abdullah di dalam rumahnya semisal anak yang beradab serta rajin, ia selalu mandi setiap pagi dan sore hari, dan dia selalu bersungguh-sungguh untuk membersihkan pakaian-pakaiannya juga kitab-kitabnya (bukubukunya)dan meletakannya dengan rapi di tempat yang khusus, dan mengelap (sisa makanan di mulut) ke pakaian atau ke dinding, akan tetapi ia menggunakan sapu tangan, dan tidak meludah ke lantai, tidak juga 
mengotori pintu dan menulis-nulis di dinding, tidak pula memanjat-manjat di pohon dan tidak melempar-lempar batu agar tidak memecahkan kaca jendela atau merusak yang lainnya Adanya Abdullah itu senantiasa mencium tangan kedua orang tuanya dan saudara-saudaranya yang lakilaki maupun saudaranya yang perempuan setiap pagi dan petang, dan ia tidak suka masuk kamar orang lain tanpa seizin yang mempunyai kamar, dan Abdullah tidak suka pula duduk bersama para pembantu, dan tidak suka pula menceritakan apaapa yang terjadi di rumahnya. Dan daripada kebiasaannya Abdullah, ia senantiasa tidur lebih awal dan bangun lebih awal pula, dan dia senantiasa menjaga shalat-shalatnya (pada waktunya), dan mengulang pelajarannya, dan dia tidak suka bermain kecuali pada waktu bermain, dan ia senantiasa mendengar nasihat-nasihat Ayah dan Ibundanya. Oleh karena itu Abdullah mendapatkan ridho kedua orang tua dan keluarganya, dan dia hidup bersama mereka dengan bahagia dan riang gembira.

11. Ibumu Yang Penyayang. (1) Ingatlah wahai Anakku, sesungguhnya Ibumu sangat capek sekali oleh kamu, ia mengandungmu selama sembilan bulan di perutnya, kemudian menyusui kamu, dan mendidik kamu dengan pendidikan yang baik hingga kamu besar, dan ia senantiasa membersihkan badan dan pakaianmu, dan menyiapkan tempat tidur dan makananmu serta menjaga kamu dari setiap gangguan. (2) Ibumu begitu sayang kepadamu, dan ia sangat mencintaimu, dan ia begitu berharap agar engkau menjadi sebaik-baiknya anak, dan ia bersama kepayahannya karena kamu ia bersabar terhadapmu, ia bahagia denganmu, dan ia sangat senang apabila kamu senang dan sehat sertai baik, ia senantiasa melihatmu, ia akan sedih jika kamu merasa sedih, atau kamu sakit, maka ia dengan segera mengantarkan atau membawamu obat, serta ia senantiasa mendoakanmu dengan kesembuhan, dan ia tidak akan beristirahat kecuali apabila kamu telah sembuh secara sempurna. (3) Lihatlah kepada adikmu yang masih kecil, bagaimanakah Ibumu capek dalam mendidiknya, dan bagaimanakah ia mencintainya dengan cinta yang amat sangat, agar kamu tahu keadaanmu dahulu waktu masih kecil.

12. Adab Seorang Anak Kepada Ibundanya. (1) Wahai Anak yang beradab! Apabila kamu telah mengetahui capeknya Ibumu di dalam mendidikmu, serta kebesaran cintanya kepadamu, maka dengan apa kamu membalasnya? Tentu kamu tidak akan mampu untuk membalas Ibumu, dan hendaklah kamu melakukan kecuali dengan adab ini: (2) Hendaknya kamu melakukan dan melaksanakan segala perintah-perintahnya, bersamaan rasa suka dan rasa hormat, dan kamu melakukan setiap sesuatu yang akan membuat hatinya senang, dan selalu 
Pengajian kitab akhlak lil banin juz pertama bagi remaja masjid Al-Mukhlisin .....

tersenyum di hadapannya, dan selalu mencium tangannya setiap hari, serta mendoakannya panjang umur serta diberikan kesehatan lahir dan batin (3) Dan hendaklah kamu berhatihatilah dari sesuatu yang menyakiti hatinya, maka jangan kamu bermuka masam apabila ia menyuruhmu, atau ketika ia marah kepadamu, dan jangan kamu berbohong kepadanya, atau mencacinya, atau bertutur kata di hadapannya dengan kata-kata yang buruk, atau kamu melihat kepadanya dengan melotot, dan jangan kamu mengangkat suara kamu di atas suaranya, dan apabila kamu meminta sesuatu kepada Ibumu, maka jangan kamu meminta kepadanya di hadapan tamu, dan apabila ia mencegahmu maka diamlah, dan jangan marah atau menangis atau merengek-rengek kepadanya.

13. Sholeh Bersama Ibundanya. Sholeh adalah anak yang berbakti kepada Ibundanya, dan pada suatu hati Ibundanya sakit, maka Sholeh begitu bersedih, dan ia meminta izin kepada gurunya untuk menemani di sisi Ibundanya untuk membantunya, karena Ibundanya tidak ada pembantu di sisinya, terkadang ia membeli obat untuk Ibunya di apotik, dan kadang-kadang ia membeli makanan dan buah-buahan di pasar, dan ia senantiasa mendahulukan setiap sesuatu/ kebutuhan Ibunya dari pada makanan ataupun obatobatan, dan ia selalu menghibur hati Ibunya dengan berbicara yang baikbaik. Dan setelah beberapa hari,
Ibunya sembuh dari sakit, maka Sholeh amat sangat senang dan riang bahagia, dan dia senantiasa berdoa kepada Allah untuk menjaga Ibundanya, serta melanggengkan kesehatannya.

14. Kasih Sayang Ayah. (1) Ketahuilah wahai Anak yang mulia, bahwa Ayahmu juga mencintaimu sebagaimana Ibumu mencintaimu, setiap hari dia keluar rumah dengan kepayahan dan kepanasan berangkat ke pasar buka toko atau lapak untuk mendapatkan uang agar dapat membiayaimu membelikanmu pakaian dan makanan dan segala kebutuhanmu, semua itu dilakukannya dengan suka cita. (2) Ayahmu juga yang menjaga kesehatanmu dan menjagamu dari hal-hal yang dapat menyakitimu, di saat engkau sakit dialah yang paling susah mencarikanmu dokter untuk mengobatimu, membelikanmu obat, dia tidak akan merasa senang sebelum kamu benar-benar sehat. Ayahmu juga lah yang senantiasa mendoakan kesehatan dan keselamatanmu. (3) Ayahmu juga yang senantiasa berpikir untuk pendidikanmu mencarikan sekolah untukmu, membelikan buku-buku pelajaran dan alat tulisnya agar kelak kamu menjadi orang yang sempurna berilmu pengetahuan, berbudi luhur serta bermanfaat untukmu dan juga masyarakatmu.

15. Adab Anak Dengan Ayahnya. (1) Wahai Anak yang tercinta, sudah seharusnya kamu bertata-krama kepada Ayahmu sebagaimana 
kepada Ibumu, mematuhi perintahnya serta menjauhi larangannya senantiasa mendengarkan nasehat-nasehatnya karena ia tidak memerintahkanmu kecuali untuk hal-hal yang manfaat, dan tidak melarangmu kecuali pada hal-hal yang membahayakanmu. (2) Seharusnya juga kamu memohon ridhanya, dengan cara menjaga buku-buku pelajaranmu, merawat pakaianmu dan segala alat-alat pelajaranmu dan menatanya dengan rapi di tempatnya, jangan sekali-kali di sia-siakan semua itu, belajarlah yang tekun dan sungguh-sungguh serta amalkan di setiap waktu. jangan memaksa Ayahmu untuk membeli sesuatu yang tidak sanggup dibelinya, dan jangan sekali kali menyakiti(bertengkar) dengan teman atau saudara saudaramu.(3) Jika orang tua telah meridaimu maka Tuhanmu akan meridaimu juga, dan niscaya kelak kamu akan bahagia di dunia dan akhirat.

16. Cinta Kasih Seorang Ayah. Ada sebuah cerita seorang anak yang keras kepala berkali-kali Ayahnya melarang agar tidak mengganggu hewan dan tidak naik pohon, akan tetapi anak itu tidak mau mendengar ucapan Ayahnya. Suatu ketika anak itu memukul seekor kucing kemudian kucing itu menggigit kakinya sampai kakinya luka berdarah sampai anak itu merasa sangat sakit, sampai ia tidak bisa tidur, tidak enak makan karena saking sakitnya, akhirnya Ayahnya memanggilkan dokter untuknya hingga Ayahnya mengeluarkan banyak biaya untuk membayar dokternya dan membeli obatnya, akan tetapi Ayahnya tidak memedulikan dengan semua itu karena kepingin anaknya segera sembuh. Setelah ia sembuh anak itu berhenti dari kebiasaan buruknya, dan berjanji kepada Ayahnya akan mengerjakan nasehat-nasehat Ayahnya, dan tidak membangkang Ayahnya sampai ia selamat dari celaka, dan hidup enak selamanya.

17. Sopan Santun Seseorang Bersama Saudaranya. (1) Saudara kandungmu baik laki atau perempuan adalah orang yang terdekat denganmu setelah kedua orang tuamu, 62 hendak membuat Ayah dan Ibu senang maka kepada saudarasaudara juga harus sopan dan santun, diantaranya dengan cara menghormati kakak-kakakmu dan mencintai mereka dengan setulus hati dan mengikuti nasehatnasehatnya, dan juga menyayangi adik-adikmu dan mencintainya setulus hati, jangan sekali kali menyakitinya dan menghinanya, jangan bertengkar dengannya, jangan pula mengambil mainan adik adikmu karena hal itu menyebabkan orang tuamu marah. (2) Jangan suka berebut masuk kamar mandi, berebut mainan, duduk di kursi atau yang lainnya. Bersabarlah dan harus ada yang mengalah salah satunya. Perilaku ini adalah salah satu cara untuk membuat orang tua senang dan mendapatkan ridhanya. Maafkanlah kesalahan saudaramu 
Pengajian kitab akhlak lil banin juz pertama bagi remaja masjid Al-Mukhlisin .....

jika mereka berbuat salah, jelaskan

kesalahannya dengan cara halus agar tidak mengulangi lagi kesalahannya, jangan sering bercanda karena bisa menyebabkan berselisih dan pertengkaran.

18. Dua Saudara Yang Saling Mencintai. Ali dan Ahmad adalah dua saudara yang saling mencintai : mereka berangkat sekolah dan pulang selalu bersama, mereka saling tolong menolong melaksanakan kewajibannya, belajar bersama di sekolah dan di rumahnya, bermain bersama di waktu bermain. Pada suatu hari, Ali membeli dua buku Akhlak lil Banin dia bertanya pada Ayahnya: Ayah mana Ahmad? Saya mau memberi hadiah buku ini padanya. Ayahnya sangat senang sekali dan memberitahukan bahwa Ahmad ada dikamarnya sedang belajar. Maka segeralah Ali ke kamarnya Ahmad, ternyata Ahmad sedang belajar, Ali mengucapkan salam dan menyerahkan bukunya dengan senang hati, Ahmad pun menerima hadiah dari Ali dengan penuh rasa syukur. Kemudian Ahmad memberikan kotak pensil kepada Ali sambil berkata, ini hadiah untukmu saudaraku, Ali senang sekali menerima dan tidak lupa mengucapkan terima kasih. Ketika gurunya mendengar kisah mereka berdua, gurunya merasa sangat senang dan memuji mereka berdua di hadapan murid-murid yang lain dan berkata, "Lihatlah anak-anak, Ali dan Ahmad, mereka sangat beruntung sekali, jadilah kalian seperti mereka agar hidup senantiasa bahagia.

19. Adab Seorang Anak Bersama Kerabatnya. (1) Anak yang baik senantiasa menghormati kerabatnya, semisal kakek neneknya, paman dan bibinya sangat ia cintai, karena mereka juga menyayanginya dan menyayangi orang tuanya.

Senantiasa ridha kepada kerabatnya, dengan arti kata mengikuti perintahnya, menyambanginya sewaktu waktu terlebih di hari raya, ketika salah satunya sakit atau ada yang melahirkan atau baru datang dari bepergian. Ikut senang dikala mereka bersenang senang dan turut prihatin ketika mereka sedih. Tidak boleh berperilaku jelek kepada salah satu dari mereka, karena hal itu bisa menyebabkan murka Allah, murka orang tua dan kerabat yang lain. (3) Anak yang baik juga senantiasa menyayangi anak-anak kerabatnya, bermain bersama, menanyakan keadaannya, tidak lalai di saat senang kecuali ketika bersama mereka. Dan seyogyanya ikut membantu kerabatnya ketika mereka membutuhkanmu, jangan sekali-kali bertikai dan memutuskan silaturahmi, tidak boleh menampakkan wajah yang tidak ramah kepada kerabat bahkan harus tersenyum dan gembira ketika bertemu dengan mereka dan berbicara dengan baik. (4) Anak yang senantiasa baik pada kerabatnya akan hidup senang dan Allah akan melancarkan rezekinya serta memanjangkan umurnya. 
20. Mustafa Bersama Kerabatnya yaitu Yahya. Mustafa adalah anak orang kaya yang sangat baik, dia tidak sombong pada sesama, dia suka membantu terutama pada kerabatkerabatnya. Suatu ketika dia melihat Yahya, kerabatnya memakai pakaian yang sudah robek, segeralah dia pulang ke rumahnya dan mengambil baju yang baru kemudian diberikan kepada Yahya dia berkata : Ambillah pakaian ini saudaraku sebagai hadiah dariku, Yahya menerima baju itu dengan berlinang air karena senang sekali dan tidak lupa mengucapkan terima kasih atas kebaikan Mustafa. Saat orang tuanya tahu cerita ini, Ayahnya senang sekali karena Mustafa telah membantu kerabatnya dan memuji kebaikan akhlaknya Mustafa.

\section{SIMPULAN}

Pengajian Kitab Akhlak Lil Banin Juz Pertama Bagi Remaja Masjid AlMukhlisin Desa Air Bagi Kecamatan Concong Alhamdulillah berjalan dengan baik walaupun masih terdapat kekurangan atau kendala di lapangan. Namun hal tersebut dapat diatasi melalui komunikasi dan keseriusan yang intens antara pemateri dengan remaja masjid.

Beberapa saran yang dapat menjadi pertimbangan bagi pelaksanaan Pengajian Kitab Akhlak Lil Banin Juz Pertama Bagi Remaja Masjid Al-Mukhlisin Desa Air Bagi Kecamatan Concong dapat dirangkum sebagai berikut; 1) hendaknya pengurus masjid dapat bekerja sama dengan tenaga pendidik untuk bersamasama merencanakan pengajian rutin dengan mengumpulkan beberapa jamaah masjid khususnya para remaja di suatu tempat yang lebih luas bukan hanya remaja masjid setempat tetapi hendaknya agar masyarakat luar dapat mengikutinya juga. 2) usaha-usaha pengajian ini hendaknya rutinitas yang berkesinambungan agar akhlak masyarakat khususnya generasi muda tambah mantap. 3) untuk mengoptimalkan pelaksanaan pengajian ini, disarankan dapat berkolaborasi dengan instansi seperti himpunan/lembaga sosial sehingga diharapkan akhlak masyarakat menjadi lebih baik, seperti; senang membantu orang lain baik dengan; harta, tenaga, ataupun pikiran yang sifatnya membangun akhlak terpuji yang sesuai dengan ajaran agama Islam.

\section{DAFTAR PUSTAKA}

Ahmad Warson Munawwir. (2002). Kamus Al-Munawwir ArabIndonesia Terlengkap, Penerbit Puataka Progressif, Surabaya, cet. 25

Ali Jarim dan Musthofa Amin. (1954). Annahwu Al-Wadhih, Daarul Ma'arif, Gontor Ponorogo, Juz 1III.

Mahmud Yunus. (1972). Kamus ArabIndonesia, Penerbit Hidakarya Agung, Jakarta

Muhammad Achmad Asseggaf. (1995). Sekelumit riwayat hidup Al-Ustadz Umar bin Achmad Baradja, Surabay: Panitia Haul ke-V.

Umar bin Achmad Baradja.tt. Akhlakul

Banin Juz Pertama, Maktabah Muhammad Ibnu Ahmad Nabahan wa Auladuhu, Surabaya, Juz 1 